\title{
Ação Antimicrobiana do Óleo de Cravo Contra Bactérias Gram Positivas e Gram Negativas
}

Giovana Carolina Bodnar (I), Erick Kenji Nishio (I), Mariane Trizotti Krupiniski (I), Renata Katsuko Takayama Kobayashi (I), Gerson Nakazato (I)

(I) UEL - Universidade Estadual de Londrina (Rodovia Celso Garcia Cid Pr 445, Km 380. Cx Postal 10011)

\section{Resumo}

O óleo de cravo-da-índia apresenta efeitos anti-inflamatório, cicatrizante e analgésico. É comumente utilizado como antimicrobiano e antifúngico, com amplo espectro de ação contra bactérias, fungos e leveduras. Seu uso tradicional é na área odontológica, como antiséptico e analgésico, sendo ativo contra bactérias orais que causam cárie e doença periodontal. $\mathrm{O}$ mecanismo de ação do óleo de cravo ocorre em nível de membrana plasmática, juntamente com a inativação de enzimas e/ou no material genético celular. É possível que parte do efeito antimicrobiano deste óleo esteja relacionado com a sua natureza fenólica. O objetivo deste trabalho foi avaliar o efeito antimicrobiano do óleo de cravo frente às bactérias Gram positivas (Staphylococcus aureus ATCC 25923, S. aureus ATCC 29213, Enterococcus faecalis ATCC 29212, E. faecium ATCC 6569, S. epidermidis 1E4248, Streptococcus mutans UA159, S. mutans 25175) e Gram negativas (Salmonella typhimurium UK1, S. enteretidis ATCC 13076, Pseudomonas aeruginosa ATCC 9027, P. aeruginosa ATCC 27853, Escherichia coli ATCC 259222, E. coli ATCC 8739, Klebsiella pneumoniae ATCC 700603, K. pneumoniae ATCC 10031), incluindo bactérias multirresistentes (S. aureus N315 e S. aureus BEC 9393). Foi realizado o teste de sensibilidade por disco difusão e teste de microdiluição em caldo de acordo com CLSI, para determinar a concentração inibitória mínima (CIM) do óleo de cravo; e curva de crescimento e morte de acordo

\footnotetext{
Referência:

Giovana Carolina Bodnar, Erick Kenji Nishio, Mariane Trizotti Krupiniski, Renata Katsuko Takayama Kobayashi, Gerson Nakazato. Ação Antimicrobiana do Óleo de Cravo Contra Bactérias Gram Positivas e Gram Negativas. In: Anais do 12을 Congresso Latinoamericano de Microbiologia e Higiene de Alimentos - MICROAL 2014 [= Blucher Food Science Proceedings, num.1, vol.1]. São Paulo: Editora Blucher, 2014. DOI 10.5151/foodsci-microal-326
} 
com NCCLS. Para as bactérias Gram positivas o diâmetro dos halos de inibição variou entre 14 e $15 \mathrm{~mm}$, e para Gram negativas a variação foi de 7 a $17 \mathrm{~mm}$. As CIMs do óleo de cravo foram 0,12\% (v/v) a 1\% para bactérias Gram negativas e de 0,5\% para Gram positivas. A curva de crescimento e morte foi realizada para S. aureus ATCC 25923 com adição de $0,5 \%$ de óleo de cravo, e em 24 horas o crescimento chegou a zero. Este trabalho mostrou o efeito do óleo de cravo contra bactérias Gram positivas e Gram negativas, incluindo as multirresistentes, sendo observado efeito maior em bactérias Gram negativas. $\mathrm{O}$ uso deste composto natural pode ser uma alternativa ao uso de antimicrobianos convencionais, uma vez que o número crescente de bactérias multiresistentes tem diminuído as opções para o tratamento de pacientes.

Palavras-Chave: Antimicrobianos, Bactérias, Óleo de cravo Agência de Fomento: $\mathrm{CNPq}$ 